Article for Discourse symposium ("Making the Difference - twenty years on") published in Discourse, 2002, 23 (3), 329 - 338.

\title{
Effectiveness, difference and sociological research
}

\section{Lyn Yates}

Faculty of Education

University of Technology, Sydney

PO Box 222

Lindfield NSW 2070.

ph 0295145230

fax 0295145620

email: lyn.yates@uts.edu.au 
For Australian sociology of education, Making the Difference (Connell, Ashenden, Kessler and Dowsett 1982) was not just a major argument, and a 'classic' point of reference. It was also an event, an intervention in ways of doing research and speaking to practice, a methodology, a textual style. In some respects its influence on the latter dimensions has been even more pervasive and long-lasting than its influence as argument or theory. It seemed, simultaneously, to mark the high point of Reproduction theories of schooling (though its authors did not see it in this way) and also a thoughtful and orchestrated attempt to intervene in the processes. For a considerable time both before and after the publication of the book itself, the research team was a prominent roadshow in Australia, speaking to and writing for many specific audiences: teachers, teacher unions, parents, press. The book itself was designed to be read by a much wider audience than the standard sociological texts, and it succeeded in this aim. Subsequently it has become more commonplace to see research and writing as constructing and powerful practices, not just neutral paths to knowledge or communication, but Making the Difference helped to show other researchers what different ways of embarking on this might look like.

In this essay, I want to give some attention to Making the Difference as a set of practices as well as as an argument or theory. I want to set its approach and arguments against some of the shifts of theoretical interest and schooling policy interest of the intervening years, and compare it with two more recent Australian projects which I think build on that important work of Connell, Ashenden, Kessler and Dowsett but also illustrate some of the impact of those intervening agendas.

At the time it appeared, Making the Difference seemed to me to make two major contributions to debates and academic work on schooling in Australia. First, it provided an accessible and convincing case that social inequalities permeated and were produced by schooling in Australia. This was a case not just about material advantages and disadvantages, which are generally easily recognizable, but about more fundamental interactions of cultures, dispositions, agendas, and in which the very organization of schooling as an institution works differentially to the advantage of some types of families and the disadvantage of others. And the book's achievement was to show in a quite accessible way how this happens in Australia, a country where people traditionally do not see 'class'; and to show how it happens in the very processes of schooling, given that, in Australia as in most countries, public debates about schooling tend to be driven by personal experience and prejudice, and cyclical fashions, and to be unsophisticated in their attention to patterns, structures and processes.

A second major achievement of the book was that it was sensitive to some important social changes beginning to take place in relation to gender, and that it made a contribution to identifying and describing gender relations in the processes of schooling. Gender had been on the agenda in terms of public policy, a women's movement, and some important feminist theories since the 1970s, but by 1982 when Making the Difference appeared, there had still been remarkably little academic education research or theorising published on this, especially from sociologists. Making the Difference described emerging developments in the gendered relations of parents, and discussed gender issues in the relations between parents, young people, teachers. It noted how the 'ruling class' (in the Australian context, the more elite and professional groups) was beginning to develop a version of 'renovated femininity' in which academic and career achievement for women was not disparaged in the way in which some writings about gender reproduction had first suggested, but that this was heightening the class 
division which permeated the private and state school differentiation in Australia. The project, in line with Connell's work more generally, also paid better attention to masculinity and its contribution to boys' outcomes than did most other work until quite recently.

As a text, Making the Difference initiated forms that became almost an Allen \& Unwin house style for their education writers: the direct, present-participle led, janus-faced title; the journalistic use of cameo pen-pictures of individuals to illustrate and embody each argument or theme; the bracketing of methodology discussion into an appendix. All these undoubtedly contribute to expanding the readership of the text and to taking it beyond an academic audience. But this style does conceal within it some issues about relations between these stories and the study design that brings them into being, that I have tried to take up in a subsequent project, discussed below.

At the time it appeared, I was excited by this study, and spent much time discussing it with colleagues and students. At this time, I also had some criticisms or arguments with the book and with the argument it set up. The book's overall argument is that the advantages and power of elite or 'ruling class' ${ }^{1}$ families are exaggerated (multiplied) and reproduced because their schools are 'organic' to their class culture, in ways that schools are not 'organic' to working class culture. The researchers argue for action to make working class schools organic to the working class: to work more closely with parents and their knowledge, their hopes and emphases, and to rid these schools of the 'competitive academic curriculum', which Making the Difference sets up as the central bogey for the reproduction of class division, by creating what would later be called the 'always already' losers. As someone whose background is working class ${ }^{2}$, I always saw the proposal for an organic working class curriculum as romanticized and rather scary.

For one thing, given globalized new economies, the presence of immigration and race as major rather than marginal features of social forms, and taking on board feminist critiques of class theories designed around traditional families and male occupations, there are major problems in talking about 'a' working class culture today, let alone identifying what it looks like if it does exist. But more importantly, if the classes are not equal in terms of power, status, know-how, I did not see how making schools have a similar relation to their class as elite schools to theirs would produce similar power. This of course is well demonstrated by subsequent events, in the international spread of the emphasis on giving parents 'choice' and 'ownership', which of course work quite differently for those of different types of class background, different amounts of market power, and different types of know-how (Ball, Bowe and Gerwitz 1996; Yates 2001).

On re-reading the book for this article, I can see that my memories as reflected in these earlier paragraphs had done it some disservice. It is itself an interesting indicator of changing fashions in theory and sociological debate, that I had mis-remembered 'organic' as a type of Bourdieuean thinking about creating a school habitus for working class kids that would no longer 'ask of them what they cannot give'. In fact, as I re-discovered, it was a concept drawn from Gramscian theories of the 'organic intellectual' as the agent of social change (or, more accurately, revolution, but that term now seems to have a rather dated ring to it). It was a concept not simply about reflecting working-class culture but was about schools reflecting

\footnotetext{
1 'Ruling class' was adapted from the work of Erik Olin Wright, and was defined here primarily in terms of fathers' jobs (with particular attention to mental/manual division of labour and to positions of authority.)

${ }^{2}$ But of course I am someone who has benefited by the old structures. As MTD rightly notes, working class successes and 'equal opportunity' concepts have been important in the legitimation of schooling as meritocratic
} 
working-class interests. The MTD researchers recognized that being an organic working-class school or teacher was not a simple matter, nor without conflict, nor one in which there was an existing working class consensus, nor one or where schools should simply try to follow working class parents' wishes:

This is not to suggest that the school can be simply an agent of present working-class purposes; it must have a critical relationship with its clientele and their experience, and be free to oppose those aspects of working-class life which are themselves oppressive. (Connell et al. 1982, p.200)

The important thing was that schools should try to work with and respect the knowledge that parents and their children brought, but also that they should try to act as agents for the interests of the class they served, 'inventing new strategies' as part of this.

Nevertheless, though I might have forgotten the specificity of the arguments made about this concept, I think my memories of my misgivings about its vision were not misplaced. MTD shows very well the negative effects of the streaming that accompany competitive curriculum forms, whether or not they are embodied in actual streams, but it is a hazy and romantic vision of what an alternative would look like, as well as one which now seems based in a different kind of world, where class interests were clear and central. Interestingly, three years after Making the Difference was published, Bob Connell published Teachers Work (Connell 1985), a second book drawn from the same project but this time based on the interviews with teachers (MTD was based on the interviews with parents and students and broad ethnographic observations of schools and homes),. Taking seriously the stories from this second book would necessitate a much more complicated sense of how schools are constrained than the competitive-academic-curriculum / organic-working-class-schooling binary. It shows teachers with socialist commitments but who are frustrated by lack of conditions for giving kids access to powerful knowledge; and it shows the importance of teachers' biographies, subjectivities, disciplinary identities and institutional constraints in shaping how they take up any reforms, and would take up a reform such as 'organic working class curriculum'.

MTD was published at a time which in hindsight looks like the end of one phase of policy and theoretical interest in schooling, and before some dominant interests of the last two decades really took hold. In Australia it succeeded a period in which there had been a real interest in trying to do something about disadvantaged schools (and in which there were nationally funded Disadvantaged Schools Programs, and also Innovations funding for schools), and in which an interest in the inequalities of girls had begun to gain some attention. In the UK, it succeeded a period when most left sociologists had first been concerned with the harm done by streaming and the advances to be made by a move to comprehensive schools, and then, in the wake of some disillusionment, had turned their attention to 'sociology of knowledge' and the kinds of dissonances the curriculum itself continued to set up on a class-differentiated (and later gender-differentiated) basis. What was just beginning, was a new hard-headed attention to 'effective' schools, and to practices that would give more power to central governments and to parents rather than professionals as the way to produce good things for children, the beginning of a period of heightened accountability, testing and competitiveness.

For years I began my postgraduate research methodology classes in education by having students read both Making the Difference and Fifteen Thousand Hours (Rutter, Maughan, Mortimore and Ouston 1979). Each was ostensibly a major research study of schools and 'making the difference'; each was addressing both how differences were made by schools, and what practices would make a difference and produce better outcomes - but there was 
almost no point of commonality between them. Fifteen Thousand Hours, sub-titled 'Secondary schools and their effects on children' and forerunner to a host of school effectiveness studies, deliberately set up its study not on schools that were socially different, but on schools that were as similar in their intakes as possible, and with controls to try to compare even more closely like with like. It did not interview parents and students about what they thought, instead it measured in fine detail some of the internal features of the schools: discipline policies, homework policies, etc. And the 'difference' it was concerned with was not social division, it was difference in school retention and success rates, difference in immediate school outcomes. Methodologically it conceptualized the object of the study in terms of factors that could be isolated, controlled, tested, compared. MTD, sub-titled 'Schools, families and social division', conceptualized its own object of study as people and institutions formed in cultural, historical and material situations, accessible to interpretation rather than tested comparison.

In Australia and in the UK, for much of the 1980s and 1990s, with one significant exception (female/male patterns), policy emphases and public debates turned away from the focus on big social patterns and schooling, and foregrounded micro issues of quality and effects of what particular schools did, particularly their differential achievements in producing the results that numeracy, literacy, year level standards, and final school certificates measured. This produced a tougher environment for schools and teachers, working against their blaming homes and circumstances for outcomes, and providing an imperative for them to focus on student achievement and be 'accountable'. Sociological work however continued to take up ever finer and more complex interests in difference and how it was produced, producing many fine studies looking at race, ethnicity, gender, disability as well as class, focussing on subjectivities and discourses, on policies and pedagogical practices, on popular cultures and new economies.

In some senses both these subsequent trajectories develop, but develop differentially, interests that were strong in MTD. The policy and public agendas continue the spotlight on differential outcomes and schooling's failures; the sociological work continue the spotlight on culture and biography in interaction with schooling. But much of this work (of both types) fails the problem of engagement and producing change that MTD attempted to take on: 'school effectiveness' studies show little sensitivity to issues of culture and 'difference' as distinct from 'factors' that can be 'controlled'; new ethnographies and critical sociology largely fail to engage the public commonsense.(Apple 2000) How to bring these together?

A recent major Australian project, the Queensland Longitudinal School Reform Study, with its associated work on 'new basics' and 'productive pedagogies', , is an interesting attempt to do just this, and interesting to visit through the lens of MTD and the subsequent history I have just outlined. The research project itself was commissioned by a state education authority, but conceived by and conducted by researchers we might broadly identify with the cultural and critical and even poststructural sociological traditions ${ }^{4}$. They overtly drew on Bernstein's concept of pedagogic message systems, and on Allan Luke's work on new literacies to critique a direction of curriculum specification and accountability that was producing dated

\footnotetext{
${ }^{3}$ See (School of Education 2001, Lingard et.al 2000, (Lingard et.al. in press)and further information on 'new basics' on the following websites: http://education.qld.gov.au/corporate/newbasics/html/library.html\#other, Http://education.qld.gov.au/corporate/new basics/html/pedagogies/pedagog.html, and http://education.qld.gov.au/corporate/newbasics/docs/nbftech.doc.

${ }^{4}$ The research team was Bob Lingard, James Ladwig, Martin Mills, Mark Bahr, David Chant, Merle Warry, Joanne Ailwood, Ros Capeness, Pam Christie, Jennifer Gore, Debra Hayes and Allan Luke.
} 
and also impossibly complex tasks for schools. But the project also took very seriously the issues of engagement with policy-makers and with the public 'common sense'. Like the MTD team, they have actively presented their work and their findings across a whole range of interest groups and geographical locations, and twenty years after MTD was launched, the new work also makes extensive use of electronic forms and websites in presenting its ideas, arguments and findings. The 'new basics' project team also has gone further than the MTD project in terms of working with the realpolitik of institutional power and of public agendas. They have accepted the policy and 'commonsense' belief in hard evidence and measurement and constructed a project designed from the perspectives of the critical sociology camp, but which takes on the forms of the 'school effectiveness' studies, including structured observational data on classrooms which can produce nice graphs and talk about 'proofs' 5 . They have taken discourse and advertising seriously, and have come up with names or slogans that do real work: 'new basics', 'productive pedagogy'. And members of the team have blurred the boundaries between the academy and the bureaucracy, by being willing to take some positions of power in the latter, not just criticizing or offering prescriptions from the base of the academy ${ }^{6}$.

One way of seeing this project, or group of projects, is as the MTD of the early $21^{\text {st }}$ century. Like $M T D$, an important issue for this research team is the poor outcomes that schooling delivers for disadvantaged groups, like MTD it recognizes the importance of engaging with parents, students and teachers, and like MTD it tries to put together the inter-relating effects of assessment, pedagogy and curriculum and their contexts and outcomes. But with the QLSRS the curriculum strategy is not to focus on the interests of one social group, the working class, via its concept of an 'organic' curriculum, but to put issues relevant to that group (and to other diverse groups, such as Aboriginal children, children from different ethnic backgrounds, children in rural environments) more visibly on the agenda for everyone.

As with MTD, in the Queensland 'new basics' project, there is an awareness that to effect critical sociological work in education involves more than putting arguments on a page, and it is interesting to reflect on the arguments it uses to carry its ideas. Reflecting the context of this globalized point in time, there is more of a gesture in this new project to the themes prominent in political and media discourse: desires to demonstrate progress, to be developing directions that will have real economic as well as social benefits. There is much explicit attention to re-assuring the readers that this is a sensible agenda, not way-out ideas of an avante-garde:

the 'Rich Tasks' agenda is based on the work of John Dewey and Lev Vygotsky (nothing particularly postmodern there, Dewey invented the 'project approach' in 1902 and Vygotsky conceptualized the zone of proximal development in 1934).

(from Allan Luke's online discussion paper on the 'new basics' project: http://education.qld.gov.au/corporate/newbasics/docs/nbftech.doc. )

\footnotetext{
${ }^{5}$ I think this part of the project is difficult to defend methodologically, given the traditions in which the research team are well versed - but I can see the high strategic value of the method.

${ }^{6}$ Allan Luke moved from the university to take up a period as Assistant Director of Education Queensland, the state education authority; and Bob Lingard has recently acccepted an appointment to chair a new schools curriculum and assessment authority in Queensland. In NSW Jennifer Gore is moving into a similar strategic position in relation to teacher education reform.
} 
And the project writing also reflects the times (at least if contemporary labour parties are a guide) by speaking a language of social consensus rather than class war. Reading MTD now, I am struck by the directness with which that study was prepared to mount a case regarding the conflicting interests of social groups and the need to take sides, a discussion that was much more common in sociological work (and mainstream politics) of the 1970s than it is today:

It is important that state school teachers should come to see themselves for what they really are: the teachers of the working class. (Connell et al. 1982, p207)

The business of the school is not propaganda; it is equipping people with the knowledge and skills and concepts relevant to remaking a dangerous and disordered world. In the most basic sense, the process of education and the process of liberation are the same. [...] Teachers too have to decide whose side they are on.

(Connell et al. 1982, p.208)

The QLSRS and its associated projects is one interesting indicator of the new emphases and politics of the past two decades and also one that puts back on the table an ongoing issue for sociological work - its appropriate relationship to policy and practice. MTD illustrated one common type of resolution to this issue: being explicitly political, and working with the groups who are losing out to produce better practices for them. The QLSRS, in the traditions of Durkheim and social solidarity, Halsey and comprehensive schooling, Coleman and early starts, more recently Giddens and a Third Way, along with the much debated 'femocrats' of Australian government bureaucracies of the 70s and 80s, is taking a brave but risky path of policy-shaping - a possible real case study test for Bourdieuean and Foucauldian theories of how the world works, or rather, of what interventions to social patterns are possible.

The second issue I want to look at further is the shape of MTD as a research enquiry into social inequalities and schooling, because its legacy and a desire to go beyond this was an important source of the design of the project on which I have spent most of my own research time over the past decade, the 12 to 18 Project, with Julie McLeod. ${ }^{7}$ The 12 to 18 Project is a qualitative, longitudinal study (a '7-Up' type study) which has followed young people of different backgrounds at four different schools, interviewing them twice a year from the beginning of secondary school, to their initial post-school year(s), and focussing on their developing identities of self, their values and decisions about future directions, their constructions of their schooling and its effects on them.

Like most of the UK studies of class difference, MTD is a study set up around overdetermined extremes: the elite ${ }^{8}$, the obvious disadvantaged. This is valuable in terms of illustrating some aspects of the cultural interaction of families and schooling: focusing on extremes highlights the non level playing-field element of how school operates. But this design tends to exaggerate a story of reproduction rather than a story of possibilities or intervention (Fifteen Thousand Hours is its mirror image in this respect). ${ }^{9}$ Importantly, it has

\footnotetext{
7 The 12 to 18 Project (1993-2000) was funded by Australia Research Council grants, plus funding from La Trobe, Deakin and University of Technology, Sydney universities. Publications include (Yates and McLeod 1996; McLeod and Yates 1997; McLeod 2000; Yates 2000a; McLeod 2001; Yates 2000b; Yates 2001), and a book is in preparation.

${ }^{8}$ And even here, I think its story of the elite blurs certain issues that Bourdieu deals with in a more differentiated way. The most elite (richest and most powerful) have less direct reliance on school success than do professionals. ${ }^{9}$ In the UK, Geoff Whitty's recent work (Whitty 2001) has given more differentiated attention both to different paths within the middle class and schooling, and to possibilities for change; though it too is broadly structured around the binary middle class/working class as compared with the sense of what happens 'in the middle'
} 
too little to say about the great bulk of children in Australia, who are 'in the middle', with backgrounds ('cultures') and schools not as easily classifiable as the ones that were the focus of the MTD study. When Julie McLeod and I set out a decade later to design a longitudinal study concerned with schools and social differences and inequalities, we wanted to set up opportunities to look more carefully at this more ordinary and less over-determined 'middle', and also to set up opportunities to not take a single group of working class or elite kids in one particular setting as representing 'working class culture' or 'ruling class culture'. Of the four schools in which we located our study, two were not readily classifiable as either advantaged or disadvantaged (and two were), and across our sites, we selected girls and boys of similar backgrounds attending different schools, and of different backgrounds at the same school, to try to look more self-consciously at what was being attributed to 'culture' or to 'school' or to the interaction of these. (Yates 1999; Yates 2000b).

In the methodological appendix of $M T D$, the researchers explain their strategy for selecting their sample, and begin a discussion of some of the ambiguities of selecting based on categorization. They originally set out to avoid confounding issues for their focus on class by avoiding working mothers, single parent families, those with parents not born in Australia, but the empirical world rapidly spoke back to them about the problematic assumptions they were making about norms and anomalies, and they found that in order to get a suitable sample, they would have to give up their search for working-class stay-at-home mothers, and not be so strict on the elimination of migrants. Feminist discussions about class are one of many developments of the past twenty years (postcolonial arguments, theorizations of ethnicity and race, poststructural work) that caution against designing studies of today in terms of categories that represented past social and economic structures and/or past understandings of what counted (by the white men who had previously got to do the theorizing). Seeking to avoid differences which confound, can mean working with an atypical representation of the population today and, even more importantly, a distorted sense of what issues of subordination and disadvantage look like (hence the debates about politics of distribution, politics of representation, and so on).

A decade after $M T D$, in the 12 to 18 Project, we decided not to select our students on predecided indicators of the demographic features that are the stock in trade of quantitative arguments about class and about schooling inequalities, but to attempt to re-hear the meaning and significance of class, ethnicity, family type, gender through what was said by the students themselves. But the interest of MTD in the perspectives of the young people it had studied, its attention to broad social patterns and developments as well as the grounded, embodied, micro-level perspectives of interviews with students and parents, and many of the insights of that research, still thread through our own study.

In terms of social inequalities, MTD was built around a picture whose basic shape was the longstanding one of class relationships and differences, but which was also interested in how issues of gender were working through that picture. The issue of the changing economy - of different types of jobs, different types of work being rewarded, different types of opportunities - is not a major part of the story in relation to class, though it is visible in relation to gender. This was another reason why, in the 12 to 18 Project, we wanted to look more across the middle. In the short term, it is clear that the most economically disadvantaged are likely to be leaving school early and ending up unemployed or in poor jobs, and the

(neither overtly advantaged elite nor over-determined disadvantaged) that we are trying to get at in relation to Australia. 
'ruling class' have plenty of safety nets and alternative strategies to keep their own children 'winning'. But if commerce, new technologies, hospitality become more important and traditional professions relatively less high paid and powerful, how does this work through in terms of emphases and choices in the school system, and in terms of who is winning and losing? This issue of the changing form of the economy has become more evident in the two decades since MTD appeared, and is a stronger backdrop of the research design of both the QLSRS (and its associated 'new basics' and 'productive pedagogies' projects) and the 12 to 18 Project.

In terms of methodology, MTD was carried out at a point where qualitative researchers were sensitive to the types of relationships they built with those in their study, but before the fullon debates about 'research as inscription' that feminist and poststructural work have so foregrounded. At the time of its publication, based on my training as a historian working with documentary texts, I disliked the decision to present as cases fictional composites rather than allow readers to see some of the un-cleaned-up stories. In the light of subsequent poststructural and feminist methodological debates, I am less sure of my grounds on that earlier attitude (in what sense do we ever in the writing have access to 'primary' evidence since not only is the interview itself constructed in a particular way, but any reporting must select heavily from the full transcript, and in any case written texts do not transparently represent embodied and spoken events), though I still do believe in using actual cases and words, rather than constructed ones. And now I would hope in a study like MTD to hear more reflexivity as to the dynamics of the interview and the active interpreting acts of the researchers ${ }^{10}$, and we have tried to take this on in the 12 to 18 Project.(McLeod and Yates 1997) But in doing so we have been again led to confront the problematics of research in relation to context and public discourse with which both MTD and QLSRS have very effectively grappled.

Put bluntly, the more one dwells on certain lines of critical thinking about methodology, the less public and practical impact one's work may have. For the qualitative researcher, methodological issues as to what weight can be put on what is claimed remain important issues for the field - but these are of almost no interest or impact in public discussions. In public discussions, 'hard evidence' and 'convincing evidence' continues to mean numerical measurable evidence. Narratives and case-studies are now a stock in trade not just of researchers but of newspapers and news broadcasts, but they are essentially intended to be illustrative of something that has been established numerically, that represents a pattern: this is what schools do, this is what young people are like. There is little interest in differentiating high and poor quality qualitative research and accounts, and a case is intended to stand for all cases rather than to sensitize the reader or viewer to difference and specificity.

Both MTD and QLSRS took strategic approaches to this problem. MTD worked up deliberately constructed illustrative stories that would engage the reader/listener; and also treated the problem as one of political mobilisation. They not only worked with teachers, schools, unions to talk about their study, but in the final pages of the appendix were suggesting the logical consequences of that model, a move to action research:

there is a real problem about research, whatever its techniques, which remains an academic intervention from outside the situations it studies. We would hope to see

\footnotetext{
${ }^{10}$ These issues are recognized and mentioned in the appendix but not tied to the acts of inscription or theorybuilding.
} 
future research being organized in a fundamentally different way - by or with the people it is ultimately supposed to benefit.

(Connell et.al 1982, p.216)

In retrospect this does sound like a product of its times, and to my mind misses the point of the picture that MTD had been able to reveal by its broader canvas. QLSRS address the problem of the public discourse and commonsense about education differently, by trying to speak from and to an existing commonsense: including a belief that teaching practices as well as outcomes can be neatly measured and compared; tying arguments to widespread public concerns about technological and social change and how Australia can be competitive; and writing in a way designed to address the fears of the public or teacher readers.

Twenty years on, the issue of how to understand why schools produce the effects and outcomes they do remains important and contentious, and the issue of inequalities (or at least 'social exclusion') is back on the agenda in a way it has not been for much of the intervening period. Making the Difference is a classic text that bears re-reading, because the problems and perspectives it took up have not gone away (though they have got more complex); because its attention to broad social effects together with the micro-level of personal meanings and emotions are ones that few subsequent studies have achieved in such a powerful way; and because the problematic of how to do engaged sociological work in particular contexts, at particular points in time is one we need to keep on revisiting. 
References:

APPLE, M. (2000) Educating the 'Right' Way: markets, standards, god and inequality (New York, Routledge).

BALL, S. J., BOWE, R., AND GERWITZ, S. (1996) School Choice, social class and distinction: the realisation of social advantage in education, Journal of Education Policy 11, no.1, pp.89-112.

CONNELL, R. W. (1985) Teachers Work, (Sydney, Allen \& Unwin).

CONNELL, R. W., ASHENDEN, D. J., KESSLER, S., AND DOWSETT, G. W. (1982) Making the Difference: Schools, Families and Social Division (Sydney, George Allen \& Unwin).

LINGARD, B., MILLS, M. \& HAYES, D. (2000) Teachers, school reform and social justice: challenging research and practice, Australian Education Researcher, 27, no.3, pp.93109.

LINGARD, B., HAYES, D. \& MILLS, M. (in press) Teachers and productive pedagogies: contextualising, conceptualising, utilising, International Studies in the Sociology of Education .

MCLEOD, J. (2000) Schooling and subjectivity in a longitudinal study of secondary students, British Journal of Sociology of Education 21, no.4, pp.501-521.

MCLEOD, J. (2001) Metaphors of the self: searching for young people's identity through inteviews, in J. MCLEOD \& K. MALONE (Eds), Researching Youth (Hobart, Australian Clearinghouse for Youth Studies).

MCLEOD, J., AND YATES, L. (1997) Can we find out about girls and boys today, or must we just settle for talking about ourselves. Dilemmas of a feminist, qualitative longitudinal research project, Australian Education Researcher 24, no.3, pp.23 - 42.

RUTTER, M., MAUGHAN, B., MORTIMORE, P. AND OUSTON, J. (1979) Fifteen thousand hours: secondary schools and their effects on children (London, Open Books).

SCHOOL OF EDUCATION, UNIVERSITY OF QUEENSLAND. L., B., Ladwig, J., Mills, M., Bahr, M., Chant, D., Warry, M., Ailwood, J., Capeness, R., Christie, P., Gore, J., Hayes, D., Luke, A.) (2001) The Queensland School Reform Longitudinal Study (2 vol). Pp. 247 . (Brisbane: State of Queensland (Department of Education)).

WHITTY, G. (2001) Education, social class and social exclusion, Journal of Education Policy 16, no.4, pp.287-295.

YATES, L. (1999) How should we tell stories about gender and class in schooling today?, in A-K Broch-Due \& A. Nilsen G.E.Birkelund (Ed), Ansvar og Protest: Kjonn, klasse og utdanning i senmodernitete, (Bergen, University of Bergn Press,).

YATES, L. (2000a) In this brave new world... Competitive schools and postmodern research: how should we tell stories about class?, Tidskrift for lararutbildning och forskning (Journal of Research in Teacher Education Sweden) 1, pp.49-67.

YATES, L. (2000b) Representing 'class' in qualitative research, in Julie McLeod and Karen Malone (Ed), Researching Youth (Hobart, Australian Clearinghouse for Youth Research,).

YATES, L. (2001) Selves, social factors, school sites and the tricky issue of 'school effects', Change: transformations in education 4, no.2, pp.15-29.

YATES, L. AND MCLEOD, J. (1996) "And how would you describe yourself?" Researchers and researched in the first stages of a qualitative, longitudinal research project, Australian Journal of Education 40, no.1, pp.88 - 103. 


\section{University Library}

\section{- M M N E R VA A gateway to Melbourne's research publications}

Minerva Access is the Institutional Repository of The University of Melbourne

Author/s:

Yates, Lyn

Title:

Effectiveness, difference and sociological research

Date:

2002-12

Citation:

Yates, L. (2002). Effectiveness, difference and sociological research. Discourse, 23(3), 329-338.

Publication Status:

Published

Persistent Link:

http://hdl.handle.net/11343/34737 